\title{
An Experimentally Validated Heat and Mass Transfer Model for Wax Deposition from Flowing Oil onto a Cold Surface
}

\author{
Luqman Mahir $^{1}$, Jieun Lee ${ }^{1}$, H Scott Fogler ${ }^{1}$, and Ronald Larson ${ }^{1}$ \\ ${ }^{1}$ University of Michigan
}

May 5, 2020

\begin{abstract}
A new transport model is proposed for paraffin wax deposition onto a cold finger from flowing wax-containing oils. The model solves transient energy and mass balances simultaneously for a reversible first-order kinetic rate for precipitation of pseudosingle-component wax, and the effects of yield stress using a critical solid wax concentration to withstand flow-induced stress at the deposit-fluid interface, Cpi. The model can predict the time evolution of the deposit thickness, and the spatial and temporal evolution of temperature and wax concentration and was validated using experiments involving a cylindrical cold finger. We found that for oils with Cpi close to zero, the deposit thickness growth is dominated by heat transfer. However, mass transfer cannot be neglected as diffusion of wax into the deposit continues to take place even after the deposit has stopped growing. For oils with non-zero Cpi, the deposit growth is slow and accompanied by occasional sloughing.
\end{abstract}

\section{Hosted file}

Mahir et al. Manuscript.pdf available at https://authorea.com/users/295961/articles/424815an-experimentally-validated-heat-and-mass-transfer-model-for-wax-deposition-fromflowing-oil-onto-a-cold-surface 